\title{
Resonance, Dissonance, Resistance and 1 Timothy 2.8-15: \\ The Eschatological Obsolescence and "Rewriting" of a Proscriptive Text
}

\section{Introduction: establishing a context}

I was told almost 40 years ago, when I was trying out topics for doctoral research, that when it came to "the role of women in the church," as the matter was configured then, and texts like 1 Timothy 2, the scholarly sun was already setting. Make what you will of that forecast [see e.g. Merz 2004: 268ff.; Madigan and Osiek 2005; Towner 2006: 190-239; Payne 2009; Mathews 2017]. As things stand today, any of the steps taken in the past by myself and others could benefit from review and revision, but I do not wish to retrace them only to arrive again at that place of intractable disagreement. That place is well enough defined, whether the actual source of disagreement is exegesis, theology, or ideology.

What I do wish to do is to adopt one last reading/listening/translating posture towards this text in an effort to hear something I may have missed, in fact something that may give me further reason to believe 
that this text is something less than a perfect, unproblematic statement about women (or wives) and their ministry in the church in relation to men (or husbands). I am aware of my bias. The posture I envisage has become typical of translation studies, especially as this "transdiscipline" reads texts in the context of their regnant literary and cultural polysystems and intertextual matrices.

Translation studies is a scholarly conversation whose own definition continues to evolve [but see Gentzler 2016]. In the course of its development, several features of an inter-cultural and polysystemic approach to translation have emerged with clarity. Translation occurs in all spaces of human life and communication, as both an action within and reaction to those spaces. As especially identified by the postcolonial and feminist critics, such as H. K. Bhabha [1994], and by writers who have occupied marginal, liminal, and subaltern social and cultural spaces, or stand with those who have, such as G. C. Spivak [2012], M. Tymoczko and E. Gentzler [2002], translation is equally and unavoidably a means of exerting power - social power, cultural power, religious power, and cognitive power. Despite positive use of such power in translation within culture, all too often translation has abetted subjugation (colonial, political, commercial, patriarchal); translators and sponsoring institutions have the power, if not the right, to tilt the language of discourse in particular directions, accentuating certain voices while intentionally diminishing, obscuring, or erasing "Other" foreign voices [see Venuti 2008].

What might seem strange is defining a biblical author (or tradition) in terms of a foreign voice, or a marginal "Other," a characterization applied by Fanon and Lacan in psychoanalysis, by Bahktin, Kristeva and Barthes in literary criticism, and by Arduini, among others, in translation studies [see esp. Arduini 2020: 25-44]. After all, when it comes to Bible translation, we in the churches are now speaking about "our Book" and we are perhaps less inclined to identify its features, values, and perspectives in terms of authentic "difference", and in any case, we regard the churches as the repository and protector of the Scriptures, charged with "familiarizing" (that is, with eliminating or neutralizing) their linguistic, historical, and cultural "difference" in order to keep it "close." In the meaning-making process, our interpretive traditions stand in for the biblical authors who cannot explain themselves or their "difference", as the authors of contemporary foreign novels might do for those who translate them and shape them for domestic consumption. Despite, however, our limited textual 
access to it (and the role of institutions in shaping that access) the foreign voice of the "Other" in a given biblical text (any ancient text, really) exists, if we are willing to hear a text in a way that reveals the phenomenon of intertextual resonance, some resulting dissonance, and what I will describe in terms of resistance.

As for 1 Timothy 2, I take for granted an immediate literary context. Located somewhere within the Pauline tradition, this is a text about men and women (or husbands and wives) that addresses both groups but focuses on women in a public (even if ecclesial) sphere. The adornment appropriate to this sphere, as that culture measured such things, is taken up, but what is behind the application of this bit of traditional reflection by the author that is, the precise nature of the excessiveness on the part of women, which women in the community are addressed, "new Roman" women, or wealthy women, or women dressing according to the current fashions and thus mimicking prostitutes and so on - remains an impenetrable and ultimately unresolvable mystery, not because there is no information, but because there is too much information, allowing for a variety of possible reconstructions. What seems inescapable is that a single ministerial activity, in which women were possibly already engaged, described as "teaching" and linked somehow to the notoriously opaque term $\alpha \dot{v} \theta \varepsilon v \tau \varepsilon i v v$, was, via this text, forbidden to them. Over the years, I have spun this in several ways [cf. Towner 2015: 205-222; 2006: 190-239], generally arriving at an imaginary scenario in which (some) women had been exercising this activity inappropriately in ways disrespectful of their husbands (under the influence of false teachers and teaching, eschatological confusion, a cultural trend, even a particular local aggravation, or some combination of these things). My own inclination has been to regard $\alpha \dot{v} \theta \varepsilon v \tau \varepsilon i ̃ v$ as a negative appraisal of an exercise of power that is somehow further descriptive of the teaching act prohibited. In the latest evolutionary stage of my imaginative reconstruction, the text envisions the relegation of teaching women/wives in this setting to the role of learner as the result of dismissal for inappropriate teaching and abuse of authority. However, as with the application of the tradition concerning appropriate adornment, so here: there is no way to penetrate completely the unknowns that surround this situation. Various features of the historical, social, and ecclesial contexts may be known, and these would include the apparent presence of opponents or false teachers in the community, social trends, and the Artemis cult so dominant in Ephesus. Thus far, however, while there is no end of possible 
reconstructions on offer, all belong to the category of the imaginative and conjectural construal.

Second, in its larger discursive and theological context, reading this text also requires locating it within some overlapping frames, and the relevance of these for interpretation is debated [see Towner 2006: 190-200, 236-238]. First is the eschatological frame, within which should be considered a Pauline notion of the present age and the incursion of salvation into it, its (potential) progressive influence on human existence, and the implications of this for such things as distinctions linked to gender. A related, more specific frame within the eschatological one is that consisting of what I have called the Pauline equality tradition as expressed in Gal 3.28; 1 Cor 12.13; Col 3.11. Also to be mentioned is that large frame of the Mediterannean world within which Christianity and culture had to be negotiated. Finally to be stressed is that, whatever we might think about texts in general, this text must be read within its own literary network; it cannot be read in isolation from other texts with which it engages in various ways. When this engagement is observed and the resonances considered, seemingly straightforward readings of the immediate text alone may be problematized. This observation in particular leads me to the posture of reading, listening, and ultimately translating I wish to adopt.

Since Kristeva unveiled Bakhtin's "dialogism" and the dynamic known as "intertextuality" (intertextualité) [see Kristeva 1969; Pfister 1985: 1-30; Allen 2000] that has since greatly influenced literary and translation studies, texts no longer enjoy the status of unsullied originality, priority, or seminality - certainly not modern texts or translations. All texts are derivative in some sense, whether this is determinate or random derivation, and whether precursor discourses are textual, social, or systemic in content. The boundaries of texts - viewed from their function and meaning - become permeable and messages "leak." It is the character of texts to resonate within a larger literary and social network of discourses (poetic, historical, classical, contemporary, religious, technical, popular, specialized, etc.), both diachronically and synchronically. Whatever texts convey, they do so in relation to other texts. Intertextuality mines the multi-directional feature of texts, and as their resonance with precursor and contemporary texts and discourses, as well as those ongoing among intended audiences, is established, their relevance and meaning are negotiated. This is, I know, a challenge. 
I will now contextualize some terms. Resonance: Every verse of 1 Tim 2:8-15 contains words, combinations and clusters of words that vector an audience to precursor texts or discourses. Of course, some of these are perhaps less remarkable and more a function of the continuity we might expect of a writing such as 1 Timothy, as in the case of $\pi \rho o \sigma \varepsilon v ́ \chi \varepsilon \sigma \theta \alpha l$ in 2.8 as it recalls the theme of prayer launched in 2.1. Others have figured prominently in the arguments over the permanence or impermanence of the teaching, such as the allusions to Genesis in 2.13-14. We will consider a few of these as we explore the matter of resonance. Dissonance: As a text takes its place in a larger discourse or tradition, both the presence of intertextuality and also the absence or omission of tradition or discourse features can attract attention by the dissonance thus created. Similarly, shifts or developments in structure and unusual vocabulary can point to aspects of dissonance. These elements of dissonance will be identified. The sum total of these textual effects, resonance and dissonance, is to create a situation of resistance and instability that anticipates the text's obsolescence, or at least its internal vulnerability.

\section{Resonance}

At this point, I simply want to describe the intertextuality or resonance of 1 Tim 2.8-15 without getting into the matter of purpose or meaning. This could be done verse by verse, but I will divide the discussion into the rough categories of diachronic and synchronic resonance, and I will not include all of the possible points of resonance with other discourses and traditions. Suffice it to say that intertextuality is a far larger phenomenon of texts than "the NT use of the OT," and the far more complex discursive network of this text could extend as far as Hellenistic-Jewish and apocryphal Christian discourses, as well as the Stoic-Cynic and other Mediterranean-wide popular philosophies (both written and oral) that reflected in some way on the theme of our text.

a. Diachronic contacts: Intentional contact with already existing precursor texts is evident in several cases. (1) In 2.8 the discussion of prayer is

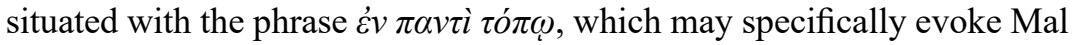
1.11 and 14 or, more generally, tie into the theme of the irresistible spread of YHWH's rule throughout the world (e.g. LXX Ps 102.22; Prov 15.3; Jer $8.3 ; 24.9 ; 51.35 ; 3$ Macc 7.12 ). Yet synchronically, this has already 
been drawn into Paul's theological reflection at 1 Cor 1.2; 2 Cor 2.14 and 1 Thess 1.8. As well, the Didache (14.3) and Targum of Pseudo Jonathan reveal an even wider discursive interest in the theme of Mal 1.11 [see Gordon 1974: 285-289]. (2) The nuanced reflection on the creation of Adam and Eve in 2.13 and specifically the verb $\pi \lambda \dot{\alpha} \sigma \sigma \omega$ create links to Gen $2.7,8,15$, but here too a much wider and possibly relevant discourse existed in Jewish tradition (2 Macc 7.23; Josephus, Ant. 1.32; ExodRab 21.6), as well as in Paul (1 Cor 11) [cf. Towner 2006: 224-233; Merz 2004: 268-372]. (3) 2.14 also creates contact with the Genesis narrative by its general contents and specifically in the use of $\dot{\varepsilon} \xi \alpha \pi \alpha \tau \dot{\alpha} \omega$ (applied to "the woman"), as well as in the combination of the personal reference $A \delta \alpha \dot{\alpha} \mu$ alongside the impersonal reference to "the woman." Here, again, this piece of Jewish and Christian tradition was a live topic in speculative strands of Judaism (Sir 25.24; Phil, Quest.Gen 1,33; All.Int 3,59-61; Pirqe R. El 13 [StrB 1.137-138]; 2 Enoch 21.6; 4 Macc 18.6-8; Gen.Rab. 18.6), in Pauline teaching (2 Cor 11.3; 1 Cor 11.3ff.), and in texts preserved in later Gnostic writings [see Rudolph 1983: 211-212, 215-216, 270-272; Kroeger and Kroeger 1992: 105-120]. (4) In my opinion, the atmosphere of redemptive promise generated by $2.15 \mathrm{a}$, and its deployment of the dis-

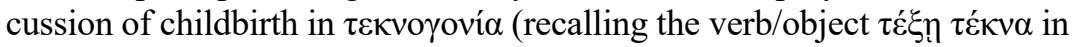
Gen 3.16), echoes at least the part of the divine pronouncement of sentence and promise directed to the serpent and the woman in Gen 3.14-16, as it also invites a redemptive reconfiguration of that story [cf. Merz 2004: 316-319]. At the same time, contemporary associations are plausible in Christian discourse alone (Gal 4.4; the traditions of the birth of Jesus in canonical and non-canonical texts), as well as some possible engagement with cultural or heretical tendencies regarding birth [see Towner 2006, 230-239; cf. Merz 2004: 298].

b. Synchronic or Contemporary resonance. I will simply list these elements (although some have already been anticipated above). (1) Generally, 2.8-15 as a whole intends to connect with the household code tradition (Colossians, Ephesians, 1 Peter) [Towner 1993; 1997]. (2) 2.8 resonates with various OT and NT cultic and prayer texts, attaching itself to the Christian tendency to reconfigure the cultus in view of the Christ event. (3) 2.9-10 bears an intertextual relationship with the tradition also reflected in 1 Pet 3.3-5 [Towner 2006: 204-212], as well as, perhaps, Philo (On the Virtues, 39; Abel and Cain, 21). Contact with an Ephesian habitus 
(via the Artemis cult, or Xenophon's Ephesiaca) is also not to be ignored [Hoag 2015: 62-84]. Moreover, if Bruce Winter is correct, intertextuality extends to the cultural discourse of reaction to "the New Roman Woman." Whether the specifics of his reconstruction hold, he has clearly identified the linguistic features of a cultural, male-shaped critique of women in the public square [2003]. (4) 2.11-12 creates resonance with 1 Cor 14.33-35 in restricting the activity of wives in relation to teaching husbands and describing propriety in terms of $\mu \alpha v \theta \alpha \dot{\alpha} \omega \omega$, vं $\sigma \tau \alpha \gamma \eta$, and $\dot{\eta} \sigma v \chi i \alpha$, as it also engages with the broader tradition reflecting upon the husband/wife relationship in terms of subordination [Towner 2006: 194-194]. (5) Reflection on the order of creation in 2.13-14 suggests resonance with such Pauline teaching as 1 Cor 11.3-16, as well as with the traditions of Jewish reflection on the creational order that developed [Towner 2006: 224-233; Merz 2004: 339-357]. (6) The forward-vectored resonance of 2.15a asks for the closing statement about "the salvation of the singular woman" and some amount of the preceding content to be mentally incorporated in the discussion of young widows, especially in in 1 Tim 5.14 (See above for the possible intertextual connection of $\tau \varepsilon \kappa v o \gamma$ ovía, and the language describing feminine propriety that follows, with competing cultural discourses on the place of women/wives in public).

When viewed in terms of intertextual resonance, this particular span of text (at least) acquires a degree of plasticity, that is, a contingency and complexity that operates on numerous levels. This is of course less troublesome if meaningful intertextuality is restricted to only the most overt citations and allusions. Indeed, some interpreters of this text, mainly noting only a proof-texting use of Genesis materials, have defined it as one of a coherent set of texts or as a consistent, authoritative articulation of an abiding ethical/theological tradition. Naturally, the intertextual resonances of a text might indeed create conformity with its discursive network, but those resonances, functioning almost as gestures that are simultaneous to the immediate text or to create echoes that provoke interest or cause confusion or astonishment and beg to be followed to their sources, might also make the text speak into its discursive network in ways that finally produce polysemy and resistance. Translation of the Bible, as with translation of other kinds of literature, typically cannot easily recreate or account for the intertextual fabric of a given text in the target language. Hearing the literary voice of the author, however, of the foreign "Other," uttering its 
shades of "difference" into the discourses of that time and culture as well as our own, requires running those resonances to ground.

\section{Dissonance}

When a writer, as the transmitter of and contributor to a tradition, addresses a topic already present in the tradition, the resultant text's meaning is a negotiation of what is present and how this compares with already existing discourses (the writer's own and others contemporary and antecedent), and what is absent. In the case of 1 Tim 2.8-15, there are, I think, several features that attract attention in this respect.

First, as noted, the form of the entire text has been compared with what is called the household code tradition [Towner 1993: 414-419; 1997: 513-520]. The binary depiction of the gendered marital unit, the vertical configuration of the relationship in terms of subordination, and the reciprocating adverb ( $\dot{\omega} \sigma \alpha \dot{\tau} \tau \omega \varsigma)$ all indicate some level of dependence upon a tradition or cultural habit (habitus) of delineating various social/familial/ civic relationships in terms of superiority and subalternity as a barometer of social respectability. The Christian appropriation (and softening) of such formulations has been noted in scholarship, but as in the case of the terse application in the prohibition of 1 Cor $14.33-35$, so here, the teaching is applied to produce an ameliorative, prohibitive effect. As in the case of the Corinthian application, the disproportionate emphasis on women and harsh tone of the prohibition together produce a dissonant effect when the specific text is considered within the intertextual flow of texts to which it belongs. This would include Paul's programmatic and sweeping dismissal of religious, social, and cultural status markers in Gal 3.28 ("There is no longer Jew or Greek, slave or free, male and female").

Second, and not unrelated, is the appearance of $\alpha v \theta \varepsilon v \tau \varepsilon \tilde{i} v$ in the prohibition. It really does not matter how problematic the etymology of the term has proved to be. Assuming this text's author stands somewhere in the Pauline tradition, or at least wishes to give this impression to his audience, the appearance of this term introduces a new wrinkle, as far as the intertextual network we have begun to trace is concerned, a surprise that also creates dissonance and turbulence.

Third, the term $\dot{\varepsilon} \xi \alpha \pi \alpha \tau \dot{\alpha} \omega$ used in 2.14 to draw attention to the primal deception of the woman creates not only a degree of resonance with existing discourses (as noted above), but it also equally works to disturb 
the cognitive terrain by its association with the Adamic "I" in Rom 7:11, where, notably, a similar reflection on the primal operation of sin in relation to the commandment is entertained but without a restrictive reference to "the woman." Then, Paul's appeal to the deception of the Eve motif and use of this specific verb in 2 Cor 11.3, in a context also employing the metaphor of the pure virgin in reference to the Corinthian church, perhaps also stretches the term's referential potential within the Pauline stream of thought. In any case, apparently 1 Tim 2.14 is not the last word on sin, the woman and the human race [cf. Merz 2004: 349-350]. (Cf. Philo's comment on the serpent as "the deceiver of man"; Questions on Genesis I.31).

Fourth, as I read Paul, a fundamental, trajectory-determining piece of tradition or gospel-theme is that which relativizes (in some sense) racial, social, and gender differentiations that had been thought to indicate relative worth or privileged status before God (probably in relation to conversion $=$ "baptized by one Spirit"; Dunn 1970: 127-131; Thiselton 2000: 997-1001). Gal 3.28, 1 Cor 12.11, and Col 3.11 indicate the existence of this equality principle and its flexibility of expression. As much as this theme may have shaped Paul's vision for ministry in the church, there seems no doubt that he had an equal concern for the social realities when it came to applying the principle and shaping its articulation for an audience. Thus, for example, in 1 Cor 12.13, the absence of the "male and female" pair may relate to the stiff measures he would take in the case of wives "speaking" in the church in disrespect of their husbands. Nevertheless, the absence of the gender pair from this text's use of the tradition produces a dissonant note that drives the hearer/reader outwards to inspect this text's intertextual environment. There is more going on than the primary text itself can fully explain, and the broader discursive network underscores what the dissonance insinuates. In the same way, though the thematic equality statement is not in evidence at all in 1 Timothy, nor does it need to be, its very presence in the intertextual fabric that relates to women or wives and their behavior in relation to men or husbands is a fixture in the discursive and traditional flow that disturbs the present text, as the absence of a string might disturb the sound produced by a violin.

On another level, I note in passing the dissonance that is created when one considers the social construction of Paul's churches, especially in the functions allotted to women such as Priscilla, Phoebe, and (possibly) Junia.

Listening carefully to the authorial, foreign voice involves patient observation of what is said, on the author's terms, and, as importantly, what 
is not said. Alterations of a theme or tradition, detectable by examination of the wider, intertextual web, as well as omissions and absences, can create dissonance, turbulence, and instability in a text. There is no formulaic explanation for this phenomenon, but both intertextual resonance and the dissonance caused by alteration and absence may serve as a text's nonverbal or meta-textual gesticulation, indicating that the meaning-making process exceeds the immediate textual boundaries.

\section{Resistance}

The questions that have occurred to me when this text is understood as awash in a sea of texts, traditions, and discourses, might be answered in various ways. Working within the discursive, conceptual, and cultural frames that house and interconnect with this text, the resonances and absences articulate something of a secondary, cross-cutting message.

Equality and Eschatology. The equality tradition thematic to Paul's gospel and a part of the broader, relevant theological terrain drags on the prohibitive text and does not allow it to run free from control as a universal. This is an aspect of eschatology meant, in Pauline terms, anyway, to determine Christian existence, but its presence (and its absence) is not the only eschatological determinant of the text. At 2.8, the resonance of Mal 1.11, 14 (and the three Pauline echoes and the larger theme of the coming to fruition of God's universal rule) invites the attentive hearer or reader to adopt a position within the new, intertextually proposed, reality of fulfillment, and this opens up the possibility of taking restrictive, interim measures with an eschatological grain of salt. Equally, the allusions to Genesis 2 in 2.13-14 are normally taken as proof texts and in isolation from what follows, with the text being analyzed almost as if the verse numbers in our scholarly editions of the Greek text were full stops. However, if 2.15a with its reference to childbearing is taken instead within the flow of what precedes, it does not allow one to stop the discursive process (choosing this but rejecting that) until the Protoevangelium (Gen 3.15-16) has been proclaimed into that primal imperfection of the Fall. Moreover, if the resonance of the closing promise of salvation calls to mind the birth of Jesus, the note of eschatological fulfillment sounded in the opening, at 2:8, receives reinforcement at the closing. This text's resonance, intertextuality, 
and discursive location determine the eschatological "shelf life" of its hortatory treatment of a contemporary imperfection.

Sensitivity to Cultural Realities. The household code shape of the text, and its resonance with that whole tradition, reflects awareness and sensitivity to social expectation and rules and the need to work with the social realities as they are. Specifics about respectable adornment for women in the public square similarly echo this cultural awareness. More specifically, the intertextual engagement with 1 Cor 14 is also instructive, for it invites the hearer/reader to think that the later text's concern was also for the behavior of wives, not women in general (in this case, related to the activity of teaching), because it put the reputation of the husband in a position of social vulnerability. As the physical details of appropriate adornment and public appearance are, however, subject to culture shift and drift, so (but perhaps more because of eschatological realities) the prohibition leveled against them (whatever the meaning of $\alpha \dot{\theta} \theta \varepsilon v \tau \varepsilon i v$ ) has an equally unstable "shelf life."

\section{A Resistant Reading/Rewriting [Translation] of the Text}

As mentioned above, incorporating the intertextual dimensions of a text in its translation or retranslation is not a simple matter, but when the voices from a text's intertextual fabric create a dialogue around the text, questioning it in various ways, rendering its conclusions (and especially its hegemonic inclinations) suspect in various ways, a "resistant" reconstruction can benefit when spaces are made for those resonant and dissonant utterances, hesitations, and silences to have their effect. Having identified various ways in which voices from the discursive network challenge the text's "first reading," I now attempt a translation that makes allowances for resistant voices. In this exercise, the reconstruction is necessarily rudimentary, unrefined, and somewhat distended, in order that the response to intertextual challenges can be underlined.

This experiment has a question behind it: Can translation be a mode of criticism? My thought is that it can; and it may be of relevance in the case of a body of literature, such as the New Testament, that is treated by its "sponsors" (the world's churches) not as mere historical description but as sacred text containing instruction for all ages. The biblical text explored above is a prime example of this notion of instruction for all ages, at least 
in some parts of the church. I adapt an approach recently championed by the literary translator, Clive Scott, whose specialty is the experimental translation of poetry [2018]. Among his innovative commitments and practices are two that I find most compelling. First, he translates for the polylingual reader who is able to read the source text and is therefore not reliant on accessing the ST only via a translation. This allows him more freedom from the narrow constraints of fidelity and reliability to the ST often especially connected with the needs of the monoglot reader. So, the experiment below is designed for those who can read the Greek NT. Second, he is committed to translating in such a way that the translation of the ST, understood as a "signifier" and not as a "signified," remains a signifier as (and after) it is transformed into the TT. The implication is that the translated text (or any literary text, really) requires engagement by the reader for signification to take place.

The NRSV text will provide a point of reference.

\section{NRSV}

${ }^{8}$ I desire, then, that in every place the men should pray, lifting up holy hands without anger or argument;

${ }^{9}$ also that the women should dress themselves modestly and decently in suitable clothing, not with their hair braided, or with gold, pearls, or expensive clothes,

${ }^{10}$ but with good works, as is proper for women who profess reverence for God.

${ }^{11}$ Let a woman learn in silence with full submission.

${ }^{12}$ I permit no woman to teach or to have authority over a man; she is to keep silent.

${ }^{13}$ For Adam was formed first, then Eve;

${ }^{14}$ and Adam was not deceived, but the woman was deceived and became a transgressor.

${ }^{15}$ Yet she will be saved through childbearing, provided they continue in faith and love and holiness, with modesty. 3:1 The saying is sure

\section{A Resistant Reconstruction:}

8 Therefore, Paul would have husbands, under fulfillment, offering prayer as priestly supplicants who embrace diversity and seek consensus. 
9-10. Similarly (under fulfillment), his concern for wives is that their outward appearance might commend their difference, that the outward might reflect respectability and modesty, rather than calling to mind the adornment of prostitutes or courtesans, and that their service to others would demonstrate their devotion to God.

11. In view of your present crisis, wives should be learners, listening intently to those who teach;

12. for Paul did not permit them to teach in ways that showed disrespect for their husbands - they must learn quietly.

13. A retrograde situation calls for a retrograde analogy: consider the order of creation when you disrespect your husband;

14. consider the primal fall into sin in which the woman played her part;

15. And yet she was promised restoration then in the announcement of the Childbirth, which came to pass as the divine has embodied the other. Wives here will now experience this restoration as they rediscover the godliness that seeks the other's best.

3.1 This adaptation continues the tradition.

\section{De-familiarizing Translation Effects:}

$2: 8$. The shift to the third person and explicit reference to Paul allow the text to be read as a continuation of Pauline tradition, and therefore in some senses as secondary, and immediately understood as derivative. "Under fulfillment" draws the implication of the intertextual contact with Mal $1: 11(14$; etc.) into the text as depicting the present as under the influence of the fulfillment of divine promise. It also conforms to the Pauline eschatological theme of equality. The existence of opposition and the hegemonic stereotyping employed to distinguish between "us" and "them" in the community suggest the translation "who embrace diversity and seek consensus" as a positive alternative to the negative, prohibited activities. Reference to the "priesthood" evokes thoughts of the divine representationmediation role of priests. 
2:9-10. The translation seeks to identify the implicit marginalization ("othering") of "wives" on the basis of cultural stereotypes, as it also seeks to valorize them, in this "present time under fulfillment," in their "other" status - in a sense co-opting or redeeming the marginalization. The reference to "others" is intentional, intended to signify a shift in categories and a redefinition of the concept.

$2: 11$. The choice of "wives" over "women" takes into account the intertextual connection with 1 Cor 14 and plays with restricting the intention of the comment; the plural generalizes the comment in a way suitable to the new rendering.

$2: 12$. The term $\alpha$ v่ $\theta \varepsilon v \tau \varepsilon \tilde{v} v$ (blended into the translation as "teach in ways that showed disrespect") is taken as describing an abusive, disrespectful attitude (an unusual word in the intertextual fabric indicating something other than an ordinary reference to "authority").

$2: 13$. The intertextual network suggests the "order of creation" be relativized.

$2: 14$. Similarly, the larger literary network (Rom 7; the ambivalence of 2 Cor 11.3; see Philo) essentially destabilizes any attempt to place ultimate blame on "Eve," suggesting a resistant alternative that indicates "Adam's" complicity and what this balancing out might imply for social behavior.

$2: 15$. Intertextuality suggests drawing out of "childbirth" the allusion to the promised seed of redemption ("restoration") and the fulfillment of this promise in terms of divine solidarity with the human other. "Restoration" is transferred to the wives of Ephesus as they practice a disposition that seeks the welfare of the other (their husbands).

3:1a. This formula has been taken as an affirmation formula, meant to authenticate the related discourse as consonant with the approved tradition. It is undoubtedly a function of the pseudepigraphical nature of the letter. I take it here as authenticating not just the specific shape of the text but even more so the legitimacy of adapting the apostolic tradition. 
Concluding Reflection. "When and where a text is written, the language in which it is inscribed, the traditions and debates within which it intervenes all come together to create a textual fabric. What a text can say is as determined by these factors as what it cannot say" [Loomba 2015: 54]. Surely more could be said about this text's literary resonances and contingent character. What I am suggesting is not only that this text is highly intertextual, but in fact that this is the nature of textuality, anyway, and so its intertextuality should rightly figure prominently in its analysis. When a text is situated, read consciously within the flow of its meaningful discursive network - when both resonance and dissonance are appreciated - immediate or first messages may be problematized. In effect, what I have called this text's intertextual gesturing, its silent but apparent "body-language," produces waves of resistance to the first message. These are aspects of instability and polyvalence that force first messages to be reevaluated on the basis of the intertextual discursive web. It is not, however, simply the instability or polyvalence of meaning in texts itself that is pertinent here. Rather, in its theological and ideological frame, the resonance of the foreign author's voice, its intentional harmonizing and disharmonizing with precursor texts and contemporary discourses, also creates a situation of cognitive instability in which to consider the conditions for the text's relevance and application, on the one hand, and its built-in and inevitable eschatological obsolescence, on the other. The resistant translation-critique offered represents one way of negotiating between the Greek text, serving as the original, with its hegemonic tendencies, its translations, and interpretations, and the resonance and dissonance created as it both engages and is engaged by its intertextual network.

\section{References}

Allen, G. (2000), Intertextuality, Routledge, London-New York.

Arduini, S. (2020), Con gli occhi dell'altro, Editoriale Jaca Book, Milano.

Dunn, J. D. G. (1970), Baptism in the Holy Spirit: A Re-examination of the New Testament Teaching on the Gift of the Spirit in Relation to Pentecostalism Today, Westminster Press, Philadelphia.

Bhabha, H. K. (1994), The Location of Culture, Routledge, London-New York. Gentzler, E. (2016), Translation and Rewriting in the Age of Post-Translation Studies, Routledge, London-New York. 
Gordon, R. P. (1974) “Targumic Parallels to Acts XIII and Didache XIV 3", NovT. 16: 285-289, https://doi.org/10.2307/1560224.

Hoag, G. G. (2015), Wealth in Ancient Ephesus and the First Letter to Timothy, Eisenbrauns, Winona Lake, Indiana.

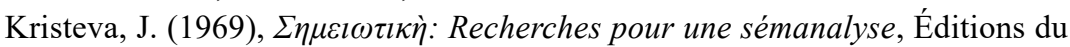
Seuil Paris, TQ.

Kroeger, R. C. and C. C. (1992), I Suffer Not a Women: Rethinking 1 Timothy 2:11-15 in Light of Ancient Evidence, Baker, Grand Rapids.

Loomba, A. (2015), COLONIALISM/POSTCOLONIALISM, Third Edition, Routledge, London-New York, TNCI.

Madigan, K. and Osiek, C. (Eds. And Trans.), (2005), Ordained Women in the Early Church: A Documentary History, The Johns Hopkins University Press, Baltimore.

Mathews, A. (2017), Gender Roles and the People of God: Rethinking What we Were Taught About Men and Women in the Church, Zondervan, Grand Rapids. Merz, A. (2004), Die fiktive Selbstauslegung des Paulus: Intertextuelle Studien zur Intention und Rezeption der Pastoralbriefe, Göttingen, Vandenhoeck \& Ruprecht, Fribourg, Academic Press, NTOA 52.

Payne, P. B. (2009), Man and Woman, One in Christ: An Exegetical and Theological Study of Paul's Letters, Zondervan, Grand Rapids.

Pfister, M. (1985), "Konzepte der Intertextualität”, in U. Broich - M. Pfister (Hgg.), Intertextualität. Formen, Funktionen, anglistische Fallstudien, Max Niemeyer Verlag, Tübingen,1-30, https://doi.org/10.1515/9783111712420.1.

Rudolph, K. (1983), Gnosis: The Nature and History of an Ancient Religion, T \& T Clark, Edinburgh.

Spivak, G. C. (2012), “The Politics of Translation”, in L. Venuti (ed.), The Translation Studies Reader, Third Edition, Routledge, London-New York, 312-330.

Thiselton, A.C. (2000), The First Epistle to the Corinthians: A Commentary on a Greek Text, Eerdmans, Grand Rapids, NIGTC.

Tymoczko, M. and Gentzler, E. (eds.), (2002), Translation and Power, University of Massachusetts Press, Amherst-Boston.

Towner, P. H. (1993), "Households and Household Codes", in G. F. Hawthorne, R. P. Martin, D. G. Reid (eds.), Dictionary of Paul and His Letters, Downers Grove, IVP, 417-419.

Towner, P. H. (1997), "Household Codes", in R. P. Martin and P. H. Davids (eds), Dictionary of the Later New Testament \& Its Developments, Downers Grove, IVP, 513-520. 
Towner, P. H. (2006), The Letters to Timothy and Titus, NICNT, Eerdmans, Grand Rapids-Cambridge, UK, NICNT.

Towner, P. H. (2015/1989), The Goal of Our Instruction: The Structure of Theology and Ethics in the Pastoral Epistles, Bloomsbury Publishing, London-New York.

Venuti, L. (2008), The Translator's Invisibility: A History of Translation, Second Edition, Routledge, London-New York.

Winter, B. W. (2003), Roman Wives, Roman Widows: The Appearance of New Women and the Pauline Communities, Cambridge University Press, Cambridge.

\begin{abstract}
This study asks whether translation might be a valid mode of (literary) criticism. It approaches a hortatory biblical text (1 Timothy 2.8-14 [3.1a]), somewhat notoriously and rigidly applied in some quarters of the church as containing timeless ethical instruction concerning women in the church, from the standpoint of its intertextual network, listening for resonance and dissonance as the relevant intertexts and precursor texts are explored. It is ultimately diagnosed as a text that is eschatologically obsolescent, and translated/rewritten, on the basis of its intertextual composition, to reflect the openness inscribed by the authorial Other.
\end{abstract}

Keywords: Bible translation, Saint Paul, intertextuality, gender, Pauline tradition 